\title{
Male reproductive success: paternity contribution to queens and workers in Formica ants
}

Received: 10 January 1997 / Accepted after revision: 22 March 1997

\begin{abstract}
The relative number of workers and female sexuals fathered by two males mated with a queen were directly assessed using microsatellite and allozyme markers in field colonies of the ants Formica exsecta and $F$. truncorum. In both species one of the two males consistently fathered more offspring than the other. There was, however, no evidence that one male might be particularly successful in fathering a disproportionally high proportion of female sexuals relative to the proportion of workers. Moreover, in F. exsecta, the proportions of worker pupae and worker adults fathered by each male did not differ significantly between cohorts. The most likely explanation for this pattern is that females store different amounts of sperm from the two males they mated with.
\end{abstract}

Key words Male reproductive success · Ants. Caste determination $\cdot$ Sperm competition

\section{Introduction}

A key feature of insect societies is reproductive division of labour, with some individuals (the queens) monopolising all or most of the reproduction and others (workers) performing primarily non-reproductive tasks

L. Keller $(\varangle) \cdot$ L. Sundström $\cdot$ M. Chapuisat

Institute of Zoology and Animal Ecology, University of Lausanne, Biology Bldg., CH-1015 Lausanne, Switzerland

Tel: (41-21) 692-41-73; Fax: (41-21) 692-41-05;

e-mail: Laurent.keller@izea.unil.ch

L. Keller $\cdot$ L. Sundström

Institute of Zoology, University of Berne, Ethological Station Hasli; Wohlenstrasse 50a, CH-3032 Hinterkappelen, Switzerland

L. Sundström

Department of Ecology and Genetics, Aarhus University,

Ny Munkegade Bldg. 540, DK-8000 Aarhus Denmark

M. Chapuisat

Museum of Zoology, P.O. Box 448, CH-1000 Lausanne 17,

Switzerland such as foraging and brood care. Considerable attention has recently focused on the proximate and ultimate factors affecting partitioning of reproduction among females in eusocial insect colonies (see Wade 1985; Pamilo 1991a; Ross and Matthews 1991; Keller 1993; Reeve and Ratnieks 1993; Bourke and Heinze 1994; Keller and Reeve 1994; Bourke and Franks 1995; Reeve and Keller 1995, 1996). These studies have revealed considerable intra- and interspecific variation in both the number of reproductive females per colony and the apportionment of maternity among them (Reeve 1991; Heinze 1993; Keller and Vargo 1993; Ross 1993). Less attention has been focused on the patrilineal elements of the breeding structure of insect societies. These elements include the number of mates per female and the variance in the apportionment of paternity among them (Wade 1985; Ross 1993). Multiple mating by queens has been reported in many eusocial Hymenoptera (Page 1985; Ross 1986; Keller and Reeve 1994; Boomsma and Ratnieks 1996).

The patrilineal elements of the breeding structure of insect societies are important parameters to consider when studying the genetic structure of colonies of social insects. Greater number of mates per female and lower variance in the apportionment of paternity among mates will tend to decrease relatedness among females produced in the colony (Wade 1985; Ross 1993; Queller 1993). Such relatedness differences may, in turn, have profound effects on various aspects of colony social organization and patterns of reproductive allocation (e.g., Bourke and Franks 1995; Ross and Keller 1995; Crozier and Pamilo 1996).

Another poorly known aspect of the breeding system of social insects is whether maternity and paternity apportionments differ for the production of worker and female sexual offspring. Ross $(1988,1993)$ found that nestmate queens differ in their direct reproductive success, as some have a larger proportion of their female offspring reared as queens. Similarly, in Formica sanguinea, the relatedness among worker pupae was significantly lower than the relatedness among sexual 
pupae produced in the same nest, suggesting that one of the co-existing queens dominates others in the production of female sexuals (Pamilo and Seppä 1994). These findings raise the question of whether males that mated with the same female may differ in the likelihood that their female offspring will develop into female sexuals rather than workers.

The aim of this study was to determine if ant males which mated with the same female differ in the proportion of workers and female sexuals they father. Ant queens mate only at the beginning of their adult lives, usually during a mating flight, and store a lifetime supply of sperm that they may use over more than 20 years in some species (Pamilo 1991b). Multiple mating by queens typically results in mixed paternity of female offspring.

We tested whether males differ in the proportion of female sexuals relative to workers they father by determining the paternity of worker and female sexuals in two ant species, Formica exsecta and F. truncorum. These two species form both monogyne (single queen per colony) and polygyne (multiple queens per colony) populations (Pamilo 1982; Pamilo and Rosengren 1984; Rosengren et al. 1993; Sundström 1993). For the purpose of this study we selected two monogyne populations. The number of sexual partners per queen and paternity contribution to workers and female sexuals were determined using DNA microsatellites and allozymes in $F$. exsecta and allozymes in F. truncorum. In $F$. exsecta we also determined whether paternity varies between cohorts of workers.

\section{Materials and methods}

\section{Methods}

We selected colonies that were headed by a doubly mated queen and produced female sexuals. In $F$. exsecta the number of sexual partners per queen was determined by typing 20 workers and 10 males (if any were produced) at two microsatellite loci (FL21 with 25 alleles and FL20 with 2 alleles, Chapuisat 1996) and three allozyme loci $(\mathrm{Mdh}+$, Aco-, Pgm +, each with 2 alleles, Sundström et al. 1996). In F. truncorum the number of sexual partners per queen was previously determined by allozyme data (Sundström 1994) and recently confirmed with microsatellites (P. Gertsch, pers. comm.).

The genotype array of the offspring produced by the multiply mated queens suggested that they each mated with two males. The probability that two fathers had identical paternal genotypes at the diagnostic loci was $2 \%$ in F. exsecta (L. Sundström, H. Alrorg, M. Chapuisat, L. Keller, unpublished work) and, combining allozyme (Sundström 1993, 1994) and microsatellite data (P. Gertsch, personal communication), less than $1 \%$ in F. truncorum. Hence, the chance was negligible that any of the colony queens in either species here assessed as double-mated was, in fact, triple-mated.

In both species colonies headed by multiply mated queens produced mostly or only males, the expected pattern if workers bias colony sex ratio to increase their inclusive fitness (Boomsma and Grafen 1990, 1991; Sundström 1994; Sundström et al. 1996). Hence, enough queen pupae could be collected from only three colonies headed by a multiply mated queen in $F$. exsecta and four colonies in F. truncorum. All samples from both species were collected in July 1995 in Tvärminne (Finland). At this time of the year colonies contain adult workers that eclosed the previous year, sexual pupae and worker pupae. Sexual and worker brood overlap partly, since sexual eggs are laid from late-April to the end of May and worker eggs are laid from late-May onwards. Worker pupae, adult workers and female sexual pupae (100 of each or as many as were found) were collected from each colony and screened at the diagnostic loci for paternity discrimination (microsatellites FL21 and FL20 in F. exsecta, and allozymes Pgk and Aco in F. truncorum). In 1995, colonies headed by multiply-mated queens produced about $32 \%$ and $30 \%$ of all female sexuals in $F$. exsecta and F. truncorum, respectively (Sundström et al. 1996; L. Sundström, unpublished work).

\section{Statistical analyses}

A non-directional binomial test (Sokal and Rohlf 1995) was used to detect significant deviations from the null expectation of equal paternity contribution. For each comparison we carried out a power analysis to determine the probability that a deviation as small as $g=0.15\left(\alpha_{2}=5 \%\right)$ from the null hypothesis of random contribution would have been detected. We used $g=0.15$ because this value is proposed by Cohen $(1988$, p. 148) as a "conventional definition of a medium departure" from the null hypothesis of equal contribution. In our study $g=0.15$ corresponds to the probability to find a significant deviation from the null expectation of equal paternity contribution in a situation where one male fathers more than $65 \%$ of the offspring. Since frequencies are discrete, the exact binomial test cannot be performed at a constant conventional $\alpha_{2}$ value (see Cohen 1988, p 150). We therefore used the nearest available value to $\alpha_{2}=5 \%$.

Differences in the proportion of workers and female sexuals that each male fathered were tested with Fisher's exact test (Sokal and Rohlf 1995). We used power tables provided for the $\chi^{2}$ test as an estimate of the sensitivity of the Fisher exact tests. For each test we determined the probability of detecting a deviation that correspond to $W=0.30(\alpha=5 \%)$ from the null hypothesis of equal contribution of males to the production of workers and female sexuals. There is unfortunately no simple way to express $W$ (the square root of the noncentrality parameter $\lambda$ divided by the total sample size) in terms of the deviation from the null hypothesis. However, the value of $W=0.30$ is commonly used as the "conventional definition of a medium association" between parameters (Cohen 1988, p. 227). We therefore used this value to determine the power of the test.

For each species we also used Fisher's test for combining probabilities (Sokal and Rohlf 1995) on the entire data set to test whether there was an overall skew in paternity of worker pupae, worker adults and queen pupae. This test is appropriate when several probabilities are obtained from independent tests of the same hypothesis.

\section{Results}

\section{Formica exsecta}

The male with highest paternity fathered between 60 and $68 \%$ of the worker pupae and between 59 and $70 \%$ of the worker adults (Table 1). One male fathered significantly more than half of the worker pupae and worker adults in two of the three colonies (Table 1). In the third colony (J21) no significant departures from equal contribution were detected, but the power of the analyses were low ( 0.31 and 0.36 , respectively) due to the relatively small sample size. A combined statistical analysis on the three colonies revealed significant differences in paternity of both worker pupae and worker adults (Fisher test for combining probabilities, 
Table 1 Number of worker pupae, worker adults and queen pupae from each of the two patrilines in Formica exsecta

\begin{tabular}{llllllrl}
\hline Colony & Patrilines & $\begin{array}{l}\text { Worker pupae } \\
\text { (proportion) }\end{array}$ & $\begin{array}{l}\text { Binomial test } \\
\text { (power) }\end{array}$ & $\begin{array}{l}\text { Worker adults } \\
\text { (proportion) }\end{array}$ & $\begin{array}{l}\text { Binomial test } \\
\text { (power) }\end{array}$ & $\begin{array}{l}\text { Queen pupae } \\
\text { (proportion) }\end{array}$ & $\begin{array}{l}\text { Binomial test } \\
\text { (power) }\end{array}$ \\
\hline $\mathrm{J} 21$ & 1 & $15(0.60)$ & $P=0.127$ & $16(0.59)$ & $P=0.345$ & $10(0.67)$ & $P=0.302$ \\
& 2 & $10(0.40)$ & $(0.31)$ & $11(0.41)$ & $(0.36)$ & $5(0.33)$ & $(0.17)$ \\
$\mathrm{J} 22$ & 1 & $42(0.68)$ & $P=0.007$ & $37(0.70)$ & $P=0.003$ & $62(0.58)$ & $P=0.037$ \\
& 2 & $20(0.32)$ & $(0.89)$ & $15(0.29)$ & $(0.54)$ & $40(0.42)$ & $(0.87)$ \\
$\mathrm{J} 31$ & 1 & $33(0.66)$ & $P=0.024$ & $33(0.66)$ & $P=0.032$ & $59(0.60)$ & $P=0.070$ \\
& 2 & $17(0.34)$ & $(0.62)$ & $17(0.34)$ & $(0.62)$ & $40(0.40)$ & $(0.87)$ \\
\hline
\end{tabular}

$\chi_{(6)}^{2}=21.51, P<0.005$, and $\chi_{(6)}^{2}=18.54, P<0.005$, respectively).

Similar results were obtained for paternity of queen pupae with one male fathering between 58 and $67 \%$ of the queen pupae. The difference in paternity was significant in one colony, marginally non-significant in another and, again, not significant in the colony from which the smaller number of individuals had been genotyped (J21). Overall the combined statistical analysis (Fisher test for combining probabilities) on the three colonies showed a significant difference between males in the parentage of queen pupae $\left(\chi_{(6)}^{2}=14.31, P<0.05\right)$.

The relative apportionment of worker pupae and worker adults by each male was remarkably similar in each of the three colonies (Table 1). In no colonies did one male contribute significantly more to worker adults compared to worker pupae (Fisher exact test $\mathbf{J} 21$, $P=0.999 ; \mathrm{J} 22, P=0.84 ; \mathrm{J} 31, P=0.999)$; The power of these comparisons was relatively high $(0.57,0.89$ and 0.85 , respectively). Overall, the probability that a difference as small as $W=0.30$ (see materials and methods) in the parentage of worker pupae and adults would have remained undetected in the colonies was only $P=0.007$. A combined statistical analysis of the three colonies also indicated that male parentage of workers did not vary between the two cohorts (Fisher test for combining probabilities, $\left.\chi_{(6)}^{2}=0.34, \mathrm{NS}\right)$.

Because there were no differences in the relative paternity of worker pupae and worker adults we combined the number of worker pupae and worker adults fathered by each male to assess their relative parentage of workers. We then tested for a differences among males in their relative success in having their progeny reared as queens rather than as workers. In none of the three colonies did males differ in their relative parentage of queen pupae and workers although the probability of
Table 2 Number of queen pupae and workers (pupae and adults) from each of the two patrilines in $F$. exsecta

\begin{tabular}{llllc}
\hline Colony & Patrilines & $\begin{array}{l}\text { Queen pupae } \\
\text { (proportion) }\end{array}$ & $\begin{array}{l}\text { Workers } \\
\text { (proportion) }\end{array}$ & $\begin{array}{l}\text { Fisher exact test } \\
\text { (power) }\end{array}$ \\
\hline $\mathrm{J} 21$ & 1 & $10(0.67)$ & $31(0.60)$ & $P=0.767$ \\
& 2 & $5(0.33)$ & $21(0.40)$ & $(0.68)$ \\
$\mathrm{J} 22$ & 1 & $62(0.58)$ & $79(0.69)$ & $P=0.201$ \\
& 2 & $40(0.42)$ & $35(0.31)$ & $(>0.99)$ \\
$\mathrm{J} 31$ & 1 & $59(0.60)$ & $66(0.66)$ & $P=0.381$ \\
& 2 & $40(0.40)$ & $34(0.34)$ & $(0.99)$ \\
\hline
\end{tabular}

detecting differences of $W=0.30$ was relatively high (Table 2). Overall, the probability of not detecting actual differences in any of the three colonies was $P<0.0001$. The combined statistical analysis of the three colonies also revealed no significant differences among males in their relative parentage of workers versus female sexuals (Fisher test for combining probabilities, $\left.\chi_{(6)}^{2}=6.57, \mathrm{NS}\right)$.

\section{Formica truncorum}

The male with highest paternity fathered between 51 and $84 \%$ of the worker pupae and between 57 and $78 \%$ of the queen pupae (Table 3). Males fathered significantly different proportions of worker pupae in two out of four colonies. Similarly, the difference in paternity of queen pupae was significant in three out of four colonies. The Fisher test for combined probabilities on the four colonies also revealed a significant difference among males in parentage of both worker pupae $\left(\chi_{(8)}^{2}=44.310\right.$, $P<0.001)$ and queen pupae $\left(\chi_{(8)}^{2}=26.124, P<0.001\right)$ fathered.
Table 3 Number of worker and queen pupae from each of the two patrilines in F. truncorum

\begin{tabular}{lllllr}
\hline Colony & Patrilines & $\begin{array}{l}\text { Worker pupae } \\
\text { (proportion) }\end{array}$ & $\begin{array}{l}\text { Binomial test } \\
\text { (power) }\end{array}$ & $\begin{array}{l}\text { Queen pupae } \\
\text { (proportion) }\end{array}$ & $\begin{array}{l}\text { Binomial test } \\
\text { (power) }\end{array}$ \\
\hline RH1 & 1 & $27(0.68)$ & $P=0.044$ & $39(0.76)$ & $P<0.001$ \\
& 2 & $13(0.33)$ & $(0.44)$ & $12(0.24)$ & $(0.62)$ \\
JSK1 & 1 & $28(0.53)$ & $P=0.784$ & $42(0.72)$ & $P<0.001$ \\
& 2 & $25(0.47)$ & $(0.58)$ & $16(0.28)$ & $(0.63)$ \\
MSK5 & 1 & $59(0.84)$ & $P<0.001$ & $79(0.78)$ & $P<0.001$ \\
& 2 & $11(0.16)$ & $(0.70)$ & $22(0.22)$ & $(0.87)$ \\
MSK11 & 1 & $25(0.51)$ & $P=0.775$ & $36(0.57)$ & $P=0.443$ \\
& 2 & $23(0.49)$ & $(0.59)$ & $27(0.43)$ & $(0.71)$ \\
\hline
\end{tabular}


In only one of the four colonies (JSK1) did one male father a significantly higher proportion of queen pupae than worker pupae (Fisher exact test, $P=0.049$, power $=0.88)$. In the three other colonies there were no significant differences among males in the parentage of queen pupae and worker pupae (RH1, $P=0.356$; MSK5 $P=0.431$; MSK11 $P=0.701)$, although the power of detecting differences of $W=0.30$ was relatively high (81, 98 and $88 \%$, respectively). Overall, there were no significant differences among males in their parentage of worker pupae and queen pupae when the data from the four colonies were considered together (Fisher test for combining probabilities $\left.\chi_{(8)}^{2}=10.49 \mathrm{NS}\right)$.

\section{Discussion}

Our results show that when queens mate with two males, one of them frequently fathers a substantially higher proportion of offspring than the other. The differences among males in parentage of worker pupae were significant in two out of three colonies in $F$. exsecta and in two out of four colonies in F. truncorum. Similarly, one male fathered a higher proportion of queen pupae, with a significant difference in one out of the three $F$. exsecta colonies and three out of the four F. truncorum colonies. The combined analyses on the entire data sets from both species further confirmed the significance of this pattern, indicating that males mated with the same queen significantly differ in their reproductive success in any one year.

In $F$. exsecta the relative proportions of worker pupae and worker adults fathered by each male were remarkably similar in all three colonies. The power of each comparison was relatively high $(57-89 \%$ per colony) so that the chance that a difference of $W=0.30$ in the parentage of worker pupae and adults would have remained undetected in any colony was only $P=0.007$. Because the adult workers were produced the previous reproductive season, this indicates that queens used a relatively constant proportion of sperm from each mate during two consecutive years. Fluctuations in paternity have been studied in a few other eusocial Hymenoptera. Long-term representation of each patriline is fairly constant in the honey bees (Crozier and Brückner 1981; Page and Metcalf 1982; Laidlaw and Page 1984; Estoup et al. 1994), but Page and Metcalf (1982) caution that this does not mean that sperm use is completely random. Indeed, Laidlaw and Page (1984) show that there are short-term (weekly or seasonal) fluctuations in sperm use which, they suggest, might be due to sperm clumping in the spermatheca. By contrast, no evidence of paternity change over time was detected in early versus late season samples in $\mathrm{Po}$ listes metricus (Metcalf and Whitt 1977) and in monthly samples in Vespula yellow jackets (Ross 1986).

In both $F$. exsecta and $F$. truncorum males did not seem to differ in their likelihood of having their female offspring reared as queens rather than as workers. In only one of the four $F$. truncorum colonies did one male father a greater proportion of queen pupae relative to the proportion of worker pupae. The numbers of offspring genotyped in the three other colonies were large enough to detect differences in parentage of $W=0.30$ with probabilities ranging between $81 \%$ and $98 \%$. Moreover, in none of the $F$. exsecta colonies did males differ in their parentage of workers and female sexuals, although the probability of detecting a significant difference was relatively high $(68-99 \%)$. Altogether, these data suggest that males do not, or only to a very moderate extent, differ in their paternity of female sexuals and workers.

This lack of a difference paternity of female sexuals and workers contrasts with the finding that, in at least two ant species (S. invicta: Ross 1988, 1993 and F. sanguinea: Pamilo and Seppä 1994), queens seem to differ in their likelihood of having their female offspring reared as queens rather than as workers. This difference between maternal and paternal effects could be explained if queens differential success to produce sexual daughters was due to a maternal effect, possibly by changing the composition of the egg. Some support for this hypothesis comes from the finding of Ross (1988) that dominance in sexual production by a given mother queen most often occured in association with a dramatic weight loss followed by death of the queen. This may suggests that biasing of female eggs toward preferential sexual development might require an important energy investment, ultimately leading to the queen death. Alternatively, only old queens may able to invest sufficient amounts of energy or other resources which may bias caste determination. More experiments are needed to test these hypotheses.

In conclusion, this study indicates that the reproductive success of two males mated with one female may differ, in that one of them on average fathers more offspring. There was, however, no evidence that one male might be particularly successful in fathering a disproportionally high proportion of female sexuals relative to the proportion of workers. Our results also suggest that the pattern of parentage did not vary between cohorts in $F$. exsecta. The simplest explanation for these results is that females store different numbers of sperm during mating, this difference translating into consistent differences in the relative number of offspring (both workers and queens) that male father. Differences among males in the number of sperm transferred to the queen's spermatheca might have several causes, such as differences in the number of sperm delivered in a single ejaculate (Baker and Bellis 1989; Cordero and Miller 1992; Keller and Passera 1992), queen's preference for the sperm of some males (see Birkhead and Møller 1992; Kempanaers et al. 1992; Madsen et al. 1992; Keller and Reeve 1995), and/or a mating order effect (Ridley 1989). In both species males considerably differ in size [dry weight: $F$. exsecta $=3.9 \pm 1.0(n=20)$, Sundström et al. 1996; F. truncorum $=6.6 \pm 0.8 \mathrm{mg}(n=20)$, Sundström 1995]. However, it is as yet unknown whether 
such size differences may translate into differences in the amount of sperm transferred during mating.

Acknowledgements We thank William Brown, Jay Evans, Francis Ratnieks and two anonymous reviewers for comments on the manuscript and Catherine Roger for laboratory assistance. This work was funded by the Swiss National Science Foundation (grants no. 31-35584.92, 31-36907.93, 31-40828.94 and 31-43330.95), and the "Fonds du 450e", University of Lausanne.

\section{References}

Baker RR, Bellis MA (1989) Number of sperm in human ejaculates varies in accordance with sperm competition theory. Anim Behav 37:867-869

Birkhead TR, Møller AP (1992) Sperm competition in birds. Evolutionary causes and consequences. Academic Press, New York

Boomsma JJ, Grafen A (1990) Intraspecific variation in ant sex ratios and the Trivers-Hare hypothesis. Evolution 44:1026-1034

Boomsma JJ, Grafen A (1991) Colony-level sex ratio selection in the eusocial Hymenoptera. J Evol Biol 3:383-407

Boomsma JJ, Ratnieks FLW (1996) Paternity in ants and social bees and wasps. Philos Trans R Soc Lond B 351:947-975

Bourke AFG, Franks NR (1995) Social evolution in ants. Princeton University Press, Princeton

Bourke AFG, Heinze J (1994) The ecology of communal breeding: the case of multiple-queen leptothoracine ants. Philos Trans R Soc Lond B 345:359-372

Chapuisat M (1996) Characterization of microsatellite loci in Formica lugubris and their variability in other ant species. Mol Ecol 5:599-601

Cohen J (1988) Statistical power analysis for the behavioral sciences. Lawrence Erlbaum, Hillsdale

Cordero A, Miller PL (1992) Sperm transfer, displacement and precedence in Ischura graellsii (Odonata: Coenogrionidae). Behav Ecol Sociobiol 30:261-267

Crozier RH, Brückner D (1981) Sperm clumping and the population genetics of Hymenoptera. Am Nat 117:561-563

Crozier RH, Pamilo P (1996) Evolution of social insect colonies: sex allocation and kin selection. Oxford University Press, Oxford

Estoup A, Solignac M, Cornuet J (1994) Precise assessment of the number of patrilines and of genetic relatedness in honeybee colonies. Proc R Soc Lond B 258:1-7

Heinze J (1993) Queen-queen interactions in polygynous ants. In: Keller L (ed) Queen number and sociality in insects. Oxford University Press, Oxford, pp 334-361

Keller L (ed) (1993) Queen number and sociality in insects. Oxford University Press, Oxford

Keller L, Passera L (1992) Mating system, optimal number of matings, and sperm transfer in the Argentine ant Iridomyrmex humilis. Behav Ecol Sociobiol 31:359-366

Keller L, Reeve HK (1994) Partitioning of reproduction in animal societies. Trends Ecol Evol 9:98-102

Keller L, Reeve HK (1995) Why do females mate multiply? The sexually selected sperm hypothesis. Adv Stud Behav 24:291-315

Keller L, Vargo EL (1993) Reproductive structure and reproductive roles in colonies of eusocial insects. In: Keller L (ed) Queen number and sociality in insects. Oxford University Press, Oxford, pp 16-44

Kempenaers B, Verheyen GJ, Van den Broeck M, Burke T, Van Broekhoven C, Dhondt AA (1992) Extra-pair paternity results from female preference for high-quality males in the blue tit. Nature 357:494-496

Laidlaw HH Jr, Page RE Jr (1984) Polandry in honey bees (Apis mellifera $\mathrm{L}$.): sperm utilization and intrcolony genetic relationships. Genetics 108:985-997

Madsen T, Shine R, Loman J, Hakansson T (1992) Why do female adders copulate so frequently? Nature 355:440-441
Metcalf RA, Whitt GS (1977) Intra-nest relatedness in the social wasp Polistes metricus. Behav Ecol Sociobiol 2:339-351

Page RE (1986) Sperm utilization in social insects. Ann Rev Entomol 31:297-320

Page RE, Metcalf RA (1982) Multiple mating, sperm utilization, and social evolution. Am Nat 119:263-281

Pamilo P (1982) Multiple mating in Formica ants. Hereditas 97:3746

Pamilo P (1991a) Evolution of colony characteristics in social insects. 2. Number of reproductive individuals. Am Nat 138:412433

Pamilo P (1991b) Life span of queens in the ant Formica exsecta. Insectes Soc 38:111-119

Pamilo P, Rosengren R (1984) Evolution of nesting strategies of ants: genetic evidence from different populations types of Formica ants. Biol J Linn Soc 21:332-348

Pamilo P, Seppä P (1994) Reproductive competition and conflicts in colonies of the ant Formica sanguinea. Anim Behav 48:12011206

Queller (1993) Genetic relatedness and its componenets in polygynous colonies of social insects. In: Keller L (ed) Queen number and sociality in insects. Oxford University Press, Oxford, pp 132-152

Reeve K (1991) Polistes. In: Ross KG, Matthews RW (eds) The social biology of wasps, Cornell University Press, Ithaca pp 99148

Reeve HK, Keller L (1995) Partitioning of reproduction in motherdaughter versus sibling associations: a test of optimal skew theory. Am Nat 145:119-132

Reeve HK, Keller L (1996) Relatedness asymmetry and reproductive sharing in animal societies. Am Nat 148:764-769

Reeve HK, Ratnieks FLW (1993) Queen-queen conflicts in polygynous societies: mutual tolerance and reproductive skew. In: Keller L (ed) Queen number and sociality in insects. Oxford University Press, Oxford, pp 45-85

Ridley M (1989) The timing and frequency of mating in insects. Anim Behav 37:535-545

Rosengren R, Sundström L, Fortelius W (1993) Monogyny and polygyny in Formica ants: The result of alternative dispersal tactics? In: Keller L (ed) Queen number and sociality in insects. Oxford University Press, Oxford, pp 308-333

Ross KG (1986) Kin selection and the problem of sperm utilization in social insects. Nature 323:798-800

Ross KG (1988) Differential reproduction in multiple-queen colonies of the fire ant Solenopsis inivcta (Hymenoptera: Formicidae). Behav Ecol Sociobiol 23:341-355

Ross KG (1993) The breeding system of the fire ant Solenopsis invicta: effets on colony genetic structure. Am Nat 141:554-576

Ross KG, Keller L (1995) Evolution of social organization: insights from fire ants and other highly eusocial insects. Annu Rev Ecol Syst 26:631-656

Ross KG, Matthews RW (1991) The social biology of wasps. Cornell University Press, Ithaca

Sokal RR, Rohlf FJ (1995) Biometry. The principles and practice of statistics in biological research, 3rd edn. Freeman, San Francisco

Sundström L (1993) Genetical population structure and sociogenetic organisation in Formica aquilonia. Behav Ecol Sociobiol 33:345-354

Sundström L (1994) Sex ratio bias, relatedness asymmetry and queen mating frequency in ants. Nature 367:266-268

Sundström L (1995) Dispersal polymorphism and physiological condition of males and females in the ant, Formica truncorum. Behav Ecol 6:132-139

Sundström L, Chapuisat M, Keller L (1996) Manipulation of sex ratios by ant workers: A test of kin selection theory. Science 274:993-995

Wade MJ (1985) The influence of multiple inseminations and multiple foundresses on social evolution. J Theor Biol 112:109121

Communicated by P. Pamilo 